\title{
La ley de los caballos: instrumento de censura y restricción a la prensa política colombiana durante el gobierno Regenerador 1886-1900
}

\author{
Clara Inés Carreño Tarazona
}

\section{RESUMEN}

Este artículo presenta un breve recorrido descriptivo y teórico de los sucesos generados en Colombia a finales del siglo XIX y comienzos del XX, básicamente con la expedición de la Ley 61 de 1888 (ley de los caballos), la cual censuró a la prensa opositora que criticaba las acciones del gobierno conservador liderado por Rafael Núñez. Para ello se presentan algunos casos, también se analiza posibles avances o efectos de la aplicación de dicha ley, frente a la libertad de expresión por parte de los medios alternativos, abordando algunos modelos teóricos prueba de ello la teoría democrático-participativa o democrático libertadora.

Palabras clave. Censura de prensa en Colombia / Ley de los caballos / Prensa política / Partidos Liberal y Conservador

Universidad de Boyacá

cicarreno@uniboyaca.edu.co

Manuscrito ID. Cubun-2019-01-06 


\title{
The law of horses: instrument of censorship and restriction to the Colombian political press during the government Regenerador 1886-1900
}

\begin{abstract}
This article presents a brief descriptive and theoretical development of the events generated in Colombia in the late nineteenth and early twentieth century, basically with the issuance of Law 61 of 1888 (Act of horses), which criticized the opposition press criticized the actions of the conservative government led by Rafael Núñez. This presents some cases, possible progress and impact of the application of this law is also discussed, with respect to freedom of expression by alternative means of addressing some theoretical models proof-democratic or participatory democratic theory liberating.
\end{abstract}

Keywords. Press censorship in Colombia; law of the horses; political press; Liberal and Conservative parties. 


\title{
La loi des chevaux : instrument de censure et restriction de la presse politique colombienne sous le gouvernement Regenerador 1886-1900
}

\begin{abstract}
RÉSUMÉ
Cet article présente un bref parcours descriptif et théorique des événements survenus en Colombie à la fin du XIXe et au début du XXe siècle, essentiellement avec la promulgation de la loi 61 de 1888 (loi sur les chevaux), qui a censuré la presse d'opposition qui critiquait les actions de la gouvernement conservateur dirigé par Rafael Núñez. Pour cela, quelques cas sont présentés, les avancées ou effets possibles de l'application de ladite loi sont également analysés, face à la liberté d'expression par les médias alternatifs, en abordant quelques modèles théoriques qui le prouvent, la théorie démocratique-participative ou libératrice démocratique.
\end{abstract}

Mots clés: Censure de la presse en Colombie ; loi des chevaux; presse politique; Partis libéral et conservateur. 


\section{LA LEY DE LOS CABALLOS: INSTRUMENTO DE CENSURA Y RESTRICCIÓN A LA PRENSA POLÍTICA COLOMBIANA DURANTE EL GOBIERNO REGENERADOR $1886-1900^{13}$}

\begin{abstract}
Se entiende por 'democratización de la comunicación' el tener una estructura de gestión del sistema de los medios masivos y de todo el sistema de comunicación de una nación, que permita a todo el pueblo participar democráticamente en las decisiones que influyen en la estructura de la comunicación pública.
\end{abstract}

\section{INTRODUCCIÓN}

En el acontecer del año de 1884 en los Estados Unidos de Colombia, apelativo constitucional del país en la época; se padecía una aguda crisis económica, social y política, debido a la disminución de las exportaciones, la desorganización administrativa, y a la fuerte oposición de los liberales radicales ${ }^{14}$, quienes acababan de liderar la guerra civil de 1885 resultando derrotados por el reelecto Presidente de la República Rafael Wenceslao Núñez Moledo, un liberal de condición que resultó contrariando los postulados ideológicos esenciales de su colectividad, generándole el apoyo directo del Partido Conservador, principal contrincante y enemigo político del grupo dominante hasta el momento.

En respuesta a la actitud liberal, Núñez Moledo relevó la Constitución Política de Rionegro por la Carta Magna de 1886. Esta aumentó los poderes del ejecutivo accediendo al predominio de la religión católica en todo el Estado, determinando un poder central, y brindándole herramientas legales para introducir medidas preventivas que afectaran el orden público. Legalmente fue la puesta en marcha de medidas adoptadas por el Ejecutivo, como represalia a las acciones opositoras del liberalismo radical que ejercía cualquier tipo de reacciones encaminadas a la desestabilización del gobierno de turno.

\footnotetext{
${ }^{13}$ Según Jorge Orlando Melo, durante la Regeneración se estableció un ordenamiento político-cultural autoritario y tradicionalista, bastante hostil a algunos aspectos asociados con la modernización económica, social, política y cultural del país. Sin embargo, al mismo tiempo los sectores dirigentes del país compartieron el anhelo del desarrollo capitalista, lo que dio al Estado y al proyecto político adelantando, más que un contenido antimodernizador, un aire contradictorio de "modernización tradicionalista", gradual y lento, que no pretendía eludir todo conflicto con las tradiciones culturales del país o con sus estructuras políticas. (Melo, 1990, pp. 23-35).

${ }^{14} \mathrm{Se}$ destaca que uno de los principales problemas políticos del país fue la firma de la Constitución de Rionegro en 1863 de iniciativa liberal, la cual organizó la estructura estatal para la asimilación de las ideas liberales y comerciales que se estaban dando. Algunas de las proposiciones determinantes, fue definir el Estado como Federal estableciendo 9 Estados Soberanos, el Presidente sólo tenía funciones delegadas de los Estados Soberanos tales como las relaciones exteriores, el manejo del ejercito del Gobierno General, la administración del crédito público, el régimen de comercio exterior, determinación de la moneda y la resolución de los problemas que surgieran entre los Estados Soberanos. Disponible en: http:// hdhc.blogspot.com/2007/05/el-liberalismo-radical-quero.html
} 
En dicho periodo se promulgaron numerosas leyes restrictivas hacia todo tipo de libertades sociales cómo fue la Ley 61 de 1888, conocida como la ley de los caballos ${ }^{15}$, la cual se convirtió en el principal instrumento de represión o castigo para aquellos que contrariaran las decisiones gubernamentales; esencialmente dirigida a los publicistas (periodistas) radicales quienes criticaban las acciones gubernamentales a través de la prensa política. La ley condenaba a prisión, exilio y pérdida de los derechos políticos a los detractores del gobierno regenerador, este caracterizado por ejecutar profundos cambios en el orden político y social a finales del siglo XIX en Colombia.

Asimismo la norma, le concedió al Ejecutivo facultades extraordinarias, para sancionar y destituir a los militares contrarios de la confianza del Gobierno. También controlar e inspeccionar a las asociaciones científicas, con el fin de evitar la propaganda revolucionaria o de enseñanzas subversivas, que atentara directamente contra los postulados del proyecto regenerador.

Justamente estas series de medidas también permitió la aprobación de normas como el Artículo L -letra usada por los Romanos que representaba lo heredado de la Ley 61 en el presente caso-, donde el Jefe de Estado expidió actos de carácter legislativos; y el
Artículo Transitorio K -letra usada por los Romanos para distinguir a los calumniadores- (Duran, 2009, p. 118), el cual le brindó amplias potestades para reprimir los abusos de la oposición, especialmente en lo concerniente a la censura de la prensa partidista. Jorge Orlando Melo, define tal periodo como la introducción de normas punitivas amplias enmarcadas bajo el argumento de prevenir a los contrincantes que deslegitimaran cualquier acción del proyecto regenerador, como fue las críticas contra la Compañía de Jesús, orden de carácter apostólico y sacerdotal, ultra gobiernista (2004). La palabra prevenir dejaba privativo al establecimiento de la censura previa, además de la irregularidad jurídica de dar al Gobierno el ejercicio de una función judicial.

Esta última disposición legal, ocasionó fuertes pugnas que convirtieron a los periódicos de origen liberal como El Espectador, El Correo Nacional, El Telegrama, El Demócrata, El Autonomista, El Debate y El Derecho, en el blanco directo de la represalia conservadora. Dicho momento fue llamado la "polémica por la libertad", que consistió en el cierre de algunos medios informativos, prohibición de la circulación de periódicos extranjeros, y la expulsión del país de destacados dirigentes del Partido Liberal. A juicio del Gobierno, estas conductas debían ser castigadas con la restricción del derecho a la publicidad.

\footnotetext{
${ }^{15}$ Fidel Cano mediante un artículo publicado en su periódico El Espectador (julio 4 de 1888), destacó el origen del nombre ley de los caballos, el cual corresponde al caso de Juan de Dios Ulloa, gobernador del Cauca para la época. Este le informó al señor ministro de gobierno por medio de un telegrama fechado el 7 de mayo último, "que en Palmira y la Pradera estaban apareciendo hacía algunos días caballerías mayores degolladas; el señor ministro Holguín puso el caso en conocimiento del concejo nacional legislativo; éste designó a los honorables delegatorios Roldán (Antonio), y Roa (Jorge) para que estudiasen el punto; la respetable comisión opinó que el hecho era gravísimo y trascendental, que indudablemente tenía por causa el odio de los liberales a la constitución...". Véase: http://www.elespectador.com/publicaciones/especial/articulo-333597-ley-de-los-caballos
} 
Miguel Antonio Caro en algunos de sus escritos políticos calificó dicho momento como injuriosos y blasfemados a la figura presidencial:

Los ultrajes dirigidos en público al Jefe de Estado se consideran como grave atentado, y no se toleran ni su represión se dilata con embrollos judiciales; porque nadie ignora que, vulnerando la autoridad, en su más conspicuo representante, se emplea el medio más eficaz para relajar el respeto de los pueblos para hacer odioso al que manda, y odioso, en su persona, el principio de autoridad; para preparar infames atentados o revoluciones a mano armada, para subvertir el orden social (Caro, 1991, p. 316).

La aplicación de tal serie de normas entre 1886 y 1909, ocasionó el cierre de varios periódicos, la persecución de periodistas y rigió la idea de que el derecho es solamente para ejercer el bien, y que, como se decía, el mal no tiene derechos. Sin embargo, este clima algo opresivo no impidió la existencia de algunos periódicos liberales ni una importante transformación en la prensa colombiana (Melo, 2004).

Entre tanto, tal coyuntura fue aprovechada por la dirigencia del partido gobiernista, para privilegiar su propia prensa, mediante la promulgación y divulgación de los ideales políticos regeneracionistas. Eso permitió que periódicos como El Nacional, El Progreso, El Porvenir y La Luz publicaran en sus páginas criterios políticos dedicados exclusivamente a la defensa de las principales tesis de Rafael Núñez. Asimismo los periódicos religiosos salvaguardadores del proyecto regeneracionista, sus ideas no sufrieron ataques, cumpliendo cabalmente la tarea de adoctrinamiento hacia la captura de adeptos y la exaltación de las virtudes de los ciudadanos.

La reacción de la prensa opositora no se hizo esperar, las críticas contra el gobierno se multiplicaron generando graves conflictos en 1889 . El resultado de tales acontecimientos generó la suspensión de siete y la multa de doce periódicos de origen radical que violaron las leyes, esencialmente en lo referente a la publicación de mensajes difamadores hacia el Gobierno de turno.

Aunado el Ejecutivo respondió con el Decreto 910 (noviembre 29 de 1889), que es adicionado al Decreto 151 sobre prensa ${ }^{16}$, donde oprime las acciones de los periodistas infractores de la norma, "será suspendido el periódico mediante multa de diez a doscientos pesos, según la gravedad del caso. Las multas las pondrá por el propio Ministro de Gobierno en la Nación y por los Gobernadores en los Departamentos y deberán ser consignadas en la Administración de Hacienda nacional del lugar en donde se publique el periódico" (Diario Oficial, 1889, p. 1113). El decreto también sancionaba a los voceadores de periódicos con arresto de tres días y a su inhabilidad para promocionar cualquier publicación.

Las acciones represivas tomadas por el Presidente de la República hasta la fecha, prácticamente contradecía su propio discurso llevado a cabo el 11 de noviembre de 1885, cuando instaló la Asamblea Constituyente que dio vía libre a la actual. El antiguo defensor de la libertad absoluta de prensa afirmó en esa oportunidad: 
La prensa debe ser antorcha y no tea, cordial y no tósigo, debe ser mensajera de verdad y no de error y calumnia, porque la herida que se hace a la honra y al sosiego es con frecuencia la más grande de todas (Melo, 2004).

En términos generales la anterior coyuntura política, puede ser entendida según Antonio Cacua Prada como censura hacia la prensa desde un juicio razonado que se da sobre algo; este puede ser favorable o desfavorable (1987, p. 284). Tal censura es un juicio aplicado a los escritos y publicaciones. Para poder enjuiciar se requiere previa ilustración sobre el tema y tener un criterio formado sobre los asuntos sometidos a su estudio y determinación. La censura es un fallo. Frente a la prensa, el censor debe revisar el material periodístico y aplicar el criterio a las normas que la entidad encargada de la censura haya determinado. Es fácil comprender que este sistema tiene por fin, no solo verificar los escritos, sino entrabar la marcha normal del periódico o de los impresos.
El Estado asume dos regímenes: el preventivo y el represivo, que a su turno se pueden ejercer en forma directa o indirecta. Es decir, el preventivo o de censura previa consiste en examinar con anterioridad a su publicación todo el material de un periódico, y suprimir lo que esté de acuerdo con las normas que tiene el censor. Mientras que el represivo, se cumple sobre la publicación hecha y tiene por fin exigir reparaciones por derechos vulnerados mediante la divulgación informativa, algo muy común en el periodo regeneracionista.

En tanto la censura directa se realiza cuando se presentan los originales, las pruebas, el diagramado del periódico o las grabaciones a las autoridades de la censura para que ellas lo revisen y le den la correspondencia autorización. La censura indirecta se efectúa mediante normas emanadas de la oficina de censura que deben cumplirse al pie de la letra, impidiendo o negando el suministro de materias primas para la edición del periódico: papel, tinta, piezas, repuestos, maquinaria, o impidiendo la circulación del impreso.

\footnotetext{
${ }^{16}$ Algunos apartes del Decreto 151 (febrero 17 de 1888) "sobre prensa", le otorgaba al Presidente de la República facultades como: $1^{\circ}$ Que la Constitución nacional (artículo 42) protege "la honra de las personas, la tranquilidad pública y el orden social", contra los abusos de la prensa; $3^{\circ}$ Que el artículo constitucional transitorio K confiere al Gobierno "la facultad de prevenir y reprimir los abusos de la prensa", "mientras no se expida la ley de prensa," y no habiéndola expedido el Cuerpo Legislativo, el Gobierno no puede dejar de cumplir con esta labor claro y terminante. Asimismo la norma Decreta: $1^{\circ}$ Los delitos y culpas que se cometen por medio de la prensa se dividen en dos clases: 1 . Delitos y culpas contra la sociedad; y 2. Delitos y culpas contra particulares. Son publicaciones ofensivas las que vulneren derechos individuales. Enseguida en el título II De las publicaciones subversivas en el artículo $4^{\circ}$ Constituye delito de imprenta contra la sociedad cualquiera de los actos contenidos en los grupos siguientes: $1^{\circ}$ Atacar la fuerza obligatoria de las instituciones o las leyes, o provocar a desobedecerlas, o tratar de justificar actos que las leyes califican de delitos, o excitar a cometerlos; $2^{\circ}$ Atacar la Religión Católica; $3^{\circ}$ Desconocer u ofender la dignidad y prerrogativas de cualquiera autoridades en orden civil o el eclesiástico; atacar las Corporaciones depositarias del poder público o las Órdenes religiosas reconocidas por el Estado; $4^{\circ}$ Atacar la institución militar; $5^{\circ}$ Tomar el nombre y representación del pueblo; combatir la legítima organización de la propiedad; concitar unas clases sociales contra otras, o concertar coaliciones con el mismo objeto; $7^{\circ}$ Publicar noticias falsas de las que pueda resultar alarma o peligro para el orden público, 0 grave daño a los intereses o crédito del Estado. [...] (Diario Oficial, 1888, p. 143).
} 
El escenario presentado en Colombia durante tal época, no podría ser más complejo. El presente papers hace parte de la investigación en curso Memoria e identidad ideológica de la prensa política en Tunja, entre 1900 a 1930, que busca destacar y sintetizar los sucesos generados en el país tras la expedición de la Ley 61 de 1888, básicamente referenciando las consecuencias generadas por la restricción de libertad de prensa luego de ser aprobada la norma que limitaba el ejercicio de la información por parte de los periódicos de inclinación liberal y conservadora, lógicamente la prensa de la municipalidad de Tunja también afrontó estas limitaciones.

Asimismo el artículo analiza posibles avances o efectos de la aplicación de dicho estatuto desde la censura de prensa, frente a la libertad de expresión por parte de los medios alternativos, abordando algunos modelos teóricos prueba de ello la teoría democrático-participativo o democrático libertadora. Lo anterior busca determinar el alcance práctico o político que pudo tener el gobierno nacional, al intentar silenciar la prensa opositora mediante la puesta en marchar de una serie de normas que reprimían las acciones de los publicistas en su mayoría ubicados en el ala del liberalismo radical.

\section{LA LEY SOBRE PRENSA, "ESTATUTOS} DE SEGURIDAD"

Las disposiciones legales adoptadas en los gobiernos de Rafael Núñez Moledo contra la prensa opositora, termina siendo incorporada por parte de sus causahabientes políticos en los siguientes años. En el gobierno de Carlos Holguín Mallarino
(1888-1892) fueron suspendidos siete periódicos, la mayoría de manera transitoria, y se impusieron quince multas.

Carlos Miguel Antonio Caro Tobar, quien presidió el país por segunda vez (1896-1898), sancionó una de las normas más pendenciera la Ley 157 de 1896, (12 de diciembre) que definió como delito de prensa las publicaciones ofensivas que vulneraran la honra de cualquier persona, y las subversivas, que son las que atentan contra el orden social y la tranquilidad pública; es el caso de, "atacar la moral cristiana o el dogma católico, y ofender las prácticas de esta religión". Este tipo de violaciones era considerado como delitos de injuria y calumnia, siendo castigados a través del Código Penal (Diario Oficial, 1897, p. 37).

Dicha ley ordenaba controvertidos artículos como fue el número quince, que decía: "todo el que quisiera publicar o "pueda ver la luz y gozar del derecho de ser voceado por las calles", tenía que dar aviso, bien al Gobernador del Departamento o bien al Ministro de Gobierno". En resumen, era obligatorio enviar una manifestación escrita en papel sellado, donde se declarará el nombre del periódico; los asuntos en que se ocupará; el nombre y nacionalidad de su propietario y director; y el nombre del establecimiento donde se editaría.

Igual exigencia recayó para los propietarios $u$ administradores de tipografías, litografías o grabado, quienes debían a partir de la promulgación de la ley, informar a los mismos entes gubernamentales, el nombre y el lugar en donde se hallaba el establecimiento. Era la forma de controlar, regularizar y hasta de amedrentar, el funcionamiento de estas 
empresas por parte del ejecutivo. Tal hecho fue considerado como una reacción incendiaria, en razón de las fuertes restricciones y censuras dadas.

Los periódicos extranjeros, no fueron ajenos a las medidas de censura adoptadas durante el régimen regeneracionista. El Decreto 286 del 27 de marzo de 1889, dictado por Carlos Holguín es adicionado al Decreto 151 de 17 de febrero de 1888 sobre imprenta. La nueva medida faculta al ministro de gobierno y a los gobernadores "para prohibir la venta pública, en las calles o agencias particulares, de los periódicos extranjeros cuya circulación sea perjudicial a las paz pública, al orden social o a las buenas costumbres" (Cacua,1958, p. 137).

La puesta en marcha de esta ley, empezó a generar desconcierto hasta en la propia tolda gobiernista, donde ya se presentaban algunas fisuras debido a la naturaleza del contenido que significaban dichas medidas presidenciales. Antes de ser sancionada la Ley de Prensa, ya se había presentado un hecho confuso con el señor Gregorio Gutiérrez Isaza, dueño del periódico de origen conservador El Comercio, cuando fue publicado el 12 de septiembre de 1889, un titular que decía: "El Calvario de la Prensa", lo cual representó a su propietario fuertes sanciones.

Otro caso fue el Senador de la República Juan Bautista Pérez y Soto, quien dirigía el periódico El Constitucional, quien votó negativamente contra la aprobación de la ley. Este escribió en mayo 17 de 1897 un artículo titulado Antimonios, donde crítica al gobierno de ejercer la traición, el despotismo, la usurpación y la votación de abyección. Tales palabras, le valieron una multa por parte del
Gobernador de Cundinamarca, al acusarlo de él delito subversivo (calumnia o el insulto al presidente).

Ya para este periodo no solamente se percibían las habituales confrontaciones partidistas entre liberales y gobierno, también se evidenció pugnas de algunos sectores del propio conservatismo, que reclamaban mayores garantías para la prensa. Al final durante la sesión legislativa del 15 de octubre de 1898 celebrada en Bogotá, resolvió derogar tal norma, aprobando la Ley 18 del año en curso, donde a través de un artículo único se destacó: "Derógase la Ley 61 de 1888, por la cual se conceden al Presidente de la República algunas facultades extraordinarias". Los mismos sectores oficialistas que en el pasado le brindaron las facultades extraordinarias al Presidente Rafael Núñez, resolvieron por restarle dichas herramientas legales de opresión, a sabiendas de la multiplicación de casos registrados en el territorio nacional que prácticamente fracturó los intereses del proyecto regeneracionista.

\section{REACCIÓN DE LA PRENSA OPOSITORA}

El caso del periódico liberal El Relator dirigido por Felipe Pérez, quien hizo parte del grupo de liberales radicales que protestaron contra las primeras medidas jurídicas y políticas implementadas en el primer gobierno de Rafael Núñez en 1880, le permitió al primero defender sus ideales oponiéndose impávidamente a las leyes de imprenta, a pesar de haber sido sentenciado por el propio Núñez al destierro. Pérez acotó en su periódico número 286 de 1888 que el artículo 45 de la Constitución Política de 1886 "toda persona tiene derecho de presentar peticiones respetuosas a las autoridades, ya 
sea por motivos de interés general, ya de interés particular, y el de obtener pronta resolución", empero estar en desacuerdo con ella, expone que la sujeción de la Prensa conforme a las leyes es una garantía, pero que debido a que la legislación aún no está lista, es arbitraria la posición del Gobierno, ya que la tranquilidad pública está siendo tratada como un resabio de facciones especialmente contra los "adversarios en influencias e ideales".

Igual reacción tuvo Antonio José Restrepo en su periódico El Sagitario, cuando en varias ocasiones criticó abiertamente a Rafael Núñez, catalogándolo como déspota, irresponsable, tirano, usurpador, etcétera. Restrepo en uno de sus escritos destacaba que la Regeneración era como entidades abstractas, no decimos sofísticas que se llaman gobierno, regeneración, orden, moral pública, buenas costumbres, religión, irresponsabilidad, \&c., \&c (EI Sagitario, 1889, p. 1).

Asimismo el periódico El Eco Liberal dirigido por el radical José María Álvarez, quien plasmó en el primer número el encabezado: periódico de oposición, le permitió criticar y denunciar los hechos del gobierno regeneracionista. Precisamente en un artículo titulado La regeneración mata, publicado el 28 de enero de 1890 reveló el reclutamiento de jóvenes para el Ejército Nacional, tomando el caso de Román Acosta, que no quería dejarse reclutar y fue asesinado a bayoneta por el sargento del batallón de Boyacá José Antonio Rodríguez.

Este hecho ya había sido discutido por Álvarez mediante una nota publicada antes del infortunio, cuando enfatizó acerca del reclutamiento de jóvenes venidos desde el campo a Bogotá:
"Entendemos que los forasteros han sido obsequiados, desde que llegaron, con un buen vestido a cada uno y buena comida. Suponemos que son temperantes que vienen a regenerar su salud y a quienes el Gobierno quiere dar muestras de su paternal protección. Otra cosa, no la pensamos" (El Eco Liberal, 1890, p. 34).

Las fuertes lluvias de críticas del periódico El Eco Liberal al gobierno, generó la suspensión de este, por el encargado a la presidencia de la República Carlos Holguín el 3 de febrero de 1890, en razón a un artículo publicado por el corresponsal de tal medio en el municipio de Medellín, sobre el ajusticiamiento de Juan de la Cruz López, reo de homicidio y llevado a cabo en esa localidad, lo cual provocó serias denuncias del informativo al acusar de hipócrita la presencia del padre Jesuita José María Gonzalo, quien se mostró insensible a las cuatro descargas y al despedazamiento del cuerpo de López (Duran, 2009, p. 288).

Por otra parte el periódico El Concurso de origen Liberal radical, pese a su corta vida, tan solo se publicaron dos ejemplares, según Carlos Alberto Duran tuvo como principal batalla de lucha la reconciliación de todos los liberales, también llevaba la voz de los pobres y los que sufrían por la regeneración (2009, p. 301). Tal medio en un artículo publicado en julio 15 de 1891, atacó a la Iglesia Católica señalando que:

siguen las matachinadas de funciones de la iglesia. ¿Será bien mirado por Dios que el clero, su inmediato representante, esquilme al pueblo para diversiones públicas, en lugar de pedir lamisca limosna para enjugar las lágrimas de los necesitados? (El Concurso). 
La estrategia represiva contra el proyecto regeneracionista fue liderada abiertamente por los liberales radicales, eso les valió ser acusados de calumniadores y entorpecedores de las principales acciones político-social del gobierno; esencialmente los primeros, reclamaban libertad de credos, libertad de expresión, separación de la Iglesia Católica del gobierno, garantizar los derechos individuales, entre otros. En tanto los segundo, defendían los principales postulados de la regeneración, como fue transformar el proyecto económico por un proyecto administrativo, la centralización política y descentralización administrativa, la imposición de una moneda estatal de tipo nacional, el papel moneda y la instauración de un Estado totalmente de ideología religiosa, una de las principales críticas del grupo opositor que reclamaban desde la Constitución de 1863 el Laicismo Estatal.

Al final las contantes acciones opresoras del proyecto de Núñez, contra los radicales generaron divisiones e inconformismo en algunos sectores del propio conservatismo llamados históricos. Estos publicaron en enero de 1896 un catálogo titulado Manifiesto de los 21, donde critican al presidente de la República Miguel Antonio Caro, expresando la unión por alcanzar la grandeza y el avance de la Nación colombiana. Además, dicho grupo reprendía la excesiva centralización impuesta, que según Carlos Duran en la práctica, terminó con una confusión de las funciones entre las distintas entidades administrativas y con un socialismo de Estado, tan corruptor para la Nación, como nocivo para los intereses políticos y económicos (2009, p. 429).

Por último Duran destaca, que las reformas solicitadas en el Manifiesto de los 21 nacieron de un análisis del momento histórico, y de una revisión de las medidas tomadas desde 1886 con el liberalismo radical. Fue además un llamado a la grandeza del Partido Conservador, para que retomara como su deber, una apertura al camino de la participación del Partido Liberal, con la valentía originada en el apoyo de los colombianos para medirse en las elecciones y de esta manera amansar los instintos bélicos del radicalismo (2009, p. 431).

\section{CENSURA DE PRENSA VERSUS LIBERTAD DE EXPRESIÓN}

Luis Huerta Guerrero sostiene, que los fundamentos de la libertad de expresión han sido elaborados desde diversas perspectivas y enfoques, que resaltan la importancia de la difusión de ideas e informaciones para el desarrollo del ser humano y su autonomía individual, el fortalecimiento de la democracia, la formación de una opinión pública libre, la garantía de otros derechos fundamentales, como el derecho a la igualdad, y la creación de un libre mercado de ideas (2010, p. 320).

Tal orden conceptual, demuestra cómo durante el periodo de la regeneración se violaron importantes deberes y derechos fundamentales sobre libertad de expresión. La negativa a poder registrar una posición ideológica contraria a los postulados del gobierno de turno, y generar espacios de debate o crítica hacia el proyecto de Rafael Núñez, fue abiertamente censurado por el Ejecutivo mediante las diversas normas expedidas por el mismo, teniendo legítimamente el consentimiento de la Constitución Política de 1886. 
Asimismo en esta línea de reflexión, se desterró literalmente la obra Areopagítica de John Milton (1644) que es citada por Hurtado (s.f.), cuando define que las restricciones a la libertad de expresión solo limitan la creatividad y paralizan la verdad, desconociendo la importancia de este derecho para el desarrollo de nuevas ideas y conocimiento por parte del ser humano. Restringir este derecho implica impedir la circulación de nuevos puntos de vista, negando la posibilidad de que exista una pluralidad de ideas, elemento imprescindible para el contraste y debate entre ellas (2010, p. 321).

La libertad de expresión cómo derecho fundamental, fue clausurada por completo a través de la Ley 61 de 1888 o ley de los caballos, el respeto y garantías democráticas que carecieron los grupos opositores, debilitaron el modelo teórico democrático, que recalca la importancia de tal derecho para el fortalecimiento institucional de cualquier nación reconocida constitucionalmente como un Estado social de derecho, identidad política que para la época Colombia ya ejercía cierto estatus político-jurídico, a pesar de la fuerte polarización entre radicales y oficialistas. Esto también algo contrario a otros países del continente, que se debatían en regímenes autoritarios.

Por otro lado se omitió la Declaración de Derechos de Virginia expedida en junio 12 de 1776, importante documento constitucional de libertad de expresión de la época. Considerada la primera declaración de derechos humanos moderna de la historia, que tuvo dieciséis secciones, de las cuales dedica el ítem número 12 a la libertad de prensa: "la libertad de imprenta es uno de los grandes baluartes de la libertad y no puede ser restringida sino por gobiernos despóticos" (Hervada, 1978).

Los hechos acontecidos en la historiografía colombiana en el momento, fue el resultado de la adhesión interna de proyectos teóricos europeos como fueron la teoría autoritaria cuya finalidad ha sido transmitir la alta cultura, llamada también "corporativista", donde existe en la sociedad una estratificación jerárquica natural desde emperadores, reyes, aristócratas, clérigo y hasta el último de la tribu. En ella cada uno tiene un papel concreto que realizar dentro de una cosmovisión sacro-religiosa (Menache, 1990) y racional. Lippman (1955, p. 81) dice que en ellas funcionan "las leyes universales del orden racional", según referencia de José Martínez Terrero en el texto teorías de comunicación.

Puede asociarse en la práctica conforme al presente trabajo, el papel de la prensa tradicional gobiernista o algunos periódicos de origen católico, al respaldar las acciones literarias del partido Conservador, que estaba bajo la batuta de Rafael Nuñez, quien trato de consolidar el proyecto regeneracionista mediante los periódicos de casa.

Asimismo el modelo teórico democrático-participativo - democrático-libertadora, fundamentado en problematizar la realidad detectando las contradicciones y se quiere liberar de ellas para crear una sociedad más democrática. También se trata directamente de que todos puedan hacer oír su voz en el foro público cultural, para lo cual se requiere creatividad (vertiente política). Por su parte la audiencia construye resignificaciones (vertiente cultural) (Martínez, 2006, p. 14). 
Tal teoría en la praxis representó los intereses de una prensa alternativa liderada por los grupos radicales, quienes defendían unos principios libertarios centralizados esencialmente en la libre expresión y crítica al gobierno de turno. Fue la oportunidad para que grupos minoritarios interactuaran en el ejercicio del derecho a la información local y a la réplica, pero en última esto se vio condicionado debido a las acciones represivas desarrolladas por el ejecutivo.

\section{CONSIDERACIONES FINALES}

1. La censura de prensa de forma indirecta durante el periodo de regeneración, fue uno de los fenómenos políticos más característicos de la época.

2. Empero, la producción de trabajos académicos relacionados con el tema es muy minúscula, la exigua publicación existente en su mayoría son descripciones historiográficas de los hechos acontecidos, estas carecen de confrontación de fuentes.

3. Por otra parte, a pesar de las limitaciones normativas o constitucionales imputadas a la prensa opositora de manera indirecta, los publicistas seguían expresando de forma clandestina, sus principales manifiestos políticos.

4. No hay duda que la prensa política de la época, se convirtió en el principal medio de expresión ideológica no solamente para el gobierno, sino también para los ciudadanos representados en los partidos políticos.

5. Lo anterior demuestra el caso de Tunja, donde circularon los periódicos políticos afines al liberalismo y conservatismo como fueron el Regenerador del Pueblo, La Linterna, entre otros.

6. El nivel cultural de los siglos XIX y parte del XX, mantuvo un nivel alto de intelectualidad en la sociedad colombiana, en razón a los diversos proyectos ideológicos importados en su mayoría de Europa, cargados de literatura crítica o postulados dogmáticos.

7. El pensamiento político durante las dos primeras décadas del siglo XX en Colombia, estuvo esencialmente marcado por ideas liberales, socialistas y nacionalistas. El conjunto de tales ideas, se convirtieron en la principal arma de combate literario de la prensa política del momento, esto generó una fuerte polarización de doctrinas entre liberales y conservadores que terminó con la censura de publicaciones contrarias al Ejecutivo.

\section{REFERENCIAS BIBLIOGRÁFICAS}

Caro, Miguel Antonio. (1909). Libertad de imprenta. Artículos publicados en "La Nación" en 1888. Bogotá: Edición Oficial-Imprenta Nacional, págs. 137.

Caro, Miguel Antonio. (1990). Escritos políticos. Primera serie. Bogotá: Instituto Caro y Cuervo, págs. 369.

Cacua Prada, Antonio. (1958). La libertad de prensa en Colombia. Bogotá: Editorial Prensa Católica, págs. 302.

Cacua Prada. (1966). Legislación de prensa en Colombia. Bogotá: Editorial El voto nacional, págs. 162. 
Cacua Prada. (1987). Libertad y responsabilidad de la prensa. Bogotá: Fundación Universitaria Los Libertadores-Colección Antonio Nariño 1, págs. 387.

Duran Sánchez, Carlos Alberto. (2009). ¿Orden impuesto o libertad confiscada?. La imposición de leyes de prensa en la regeneración (1886-1898). Bucaramanga: Universidad Industrial de Santander-UIS, págs. 593.

Hervada, J.; Zumaquero, J. M. (1978). Textos internacionales de derechos humanos. Pamplona-España.

Huerta Guerrero, Luis Alberto. (2010). Libertad de expresión: fundamentos y límites a su ejercicio. Perú: En: Pensamiento Constitucional (año XIV número 14), págs.320-344.

Manifiestos. S.A. (1896). Imprenta del Heraldo. Bogotá.

Martínez Terrero, José. (2006). Teorías de comunicación. Universidad Católica Andrés Bello Núcleo Guayana-: Venezuela. págs. 100.

Menache, S. (1990). VOX DEI: COMMUNICATION IN THE MIDDLE AGES. New York: Oxford University Press.

Melo, Jorge Orlando. (1990). Algunas consideraciones globales sobre modernidad y modernización en el caso colombiano. Bogotá: En: Análisis político-IEPRI, (número 10 mayo-agosto), págs. 23-35.
(2004). La Libertad de Prensa

en Colombia: pasado y perspectivas actuales. Recuperado de http://www.jorgeorlandomelo.com/libertad_prensa.htm

Milton, John. (1644). Areopagítica. Traducción y prólogo de José Carner. Buenos Aires: Fondo de Cultura Económica.

\section{PERIÓDICOS CONSULTADOS}

El Concurso. (1891, julio 15), Bogotá.

El Eco Liberal. (1890, enero 28), número 10.

Bogotá, p. 37.

Diario Oficial. (1888, febrero 17), número 7.299. Bogotá, p. 143.

Diario Oficial. (1889, noviembre 29), número 7.931. Bogotá, p. 1113.

Diario Oficial. (1897,enero 12), número 10.233. Bogotá, p. 37.

El Espectador 125 años. (2012, marzo 21) La Ley de los caballos. Editorial de Fidel Cano Gutiérrez. Bogotá.

El Relator. (1888, julio 27), número 286. Bogotá. 